\title{
José Ronzón
}

Profesor-investigador del Departamento de Humanidades de la Universidad Autónoma Metropolitana, Unidad Azcapotzalco. Sociólogo por la Universidad Veracruzana y doctor en Historia por El Colegio de México. Miembro del Sistema Nacional de Investigadores desde 1997. Autor de diversos trabajos sobre historia, historiografía de México, historia de la cultura y relaciones diplomáticas en los puertos del Caribe durante los siglos XIX y XX. Coordinador de los libros Fomatos, géneros y discurso y Reflexiones en torno a la bistoriografía contemporánea, ambos publicados por la UAM-Azcapotzalco.

\section{Resumen}

Este artículo tiene por objeto evidenciar la transformación de la región económica Golfo-Caribe durante la segunda mitad del siglo XIX. Se pretende mostrar la forma en que el espacio caribeño fue incorporado a un proyecto de desarrollo económico de alcances macrorregionales. El artículo analiza la creciente presencia de Estados Unidos en la región, convirtiéndose este país en un fuerte competidor de otros inversionistas, principalmente europeos.

Palabras clave:

Golfo-Caribe, región, expansionismo económico, Estados Unidos, historia del Caribe, siglo XIX.
Abstract

This article shows the economic changes in the Gulf of Mexico and the Caribbean Sea during the second half of the XIX century. It explores the way in which the Caribbean region was incorporated to an economic scheme of macroregional reach. The article focuses on the growing presence of the United States in the area, which turned this nation into a strong competitor of European capital.

Key words:

Gulf-Caribbean, region, economic expansionism, United States, Caribbean history, XIX century.

Fecha de recepción: mayo de 2002

Fecha de aceptación: septiembre de 2002 


\title{
Reflexiones en torno a la conformación de la región económica Golfo-Caribe durante la segunda mitad del siglo XIX
}

\author{
José Ronzón
}

$A$ lo largo del siglo XIX, la región del Golfo-Caribe fue un espacio en donde confluyó una serie de intereses políticos y económicos. Estos últimos dibujaron una dinámica caracterizada por la necesidad de apropiarse y controlar el espacio marítimo. La actividad comercial y de navegación que allí se desarrolló determinaron una región en la cual concurrieron comerciantes, inversionistas y capitales que conformaron un espacio de interés del naciente capitalismo americano.

Este artículo tiene por objeto mostrar cómo se conformó el escenario económico en función de las motivaciones geopolíticas que figuraban en la región del GolfoCaribe $^{1}$ durante el último cuarto del siglo xIX. Se pretende mostrar la forma en que el espacio fue incorporado a un proyecto de desarrollo económico mayor y de alcances macrorregionales. La intención es brindar un panorama de cómo se conformó una región mercantil en función de una tradición de expansionismo económico. Uno de los problemas que dan origen a este estudio es el hecho de la fuerte presencia que Estados Unidos comienza a

\footnotetext{
${ }^{1}$ Por tegión Golfo-Caribe se entiende al gran espacio que forman el Golfo de México y la parte norte del mar Caribe.
}

tener en la región hacia las últimas décadas del siglo XIX y que poco a poco lo va convirtiendo en un competidor respetable frente a otros capitales e inversiones de origen principalmente europeo.

El trabajo se fundamenta en una revisión historiográfica que retoma algunos argumentos esbozados en los estudios históricos contemporáneos. No es un balance bibliográfico, sino una reflexión, a manera de ensayo, de la construcción de una región mercantil inscrita en el proceso de expansionismo decimonónico. Muchos de los trabajos revisados constituyen obras clásicas dentro de la historiografía caribeña y latinoamericana, como las investigaciones de Julio Le Riverend, Ramiro Guerra o Rory Miller; otros, de publicación más reciente, resultan sugerentes por sus planteamientos de largo alcance y abren nuevas discusiones, como los de José Piqueras, Fe Iglesias, Laura Muñoz o Rosario Rodríguez.

El trabajo se divide en dos apartados; en el primero se reflexiona en torno a los capitales e inversiones, su origen, circulación y presencia en el área Golfo-Caribe; mientras que en el segundo se analiza la composición de la producción. Se es consciente de que el panorama económico comprende otros factores como los circuitos mercantiles, los grupos de poder, etc. Sin 


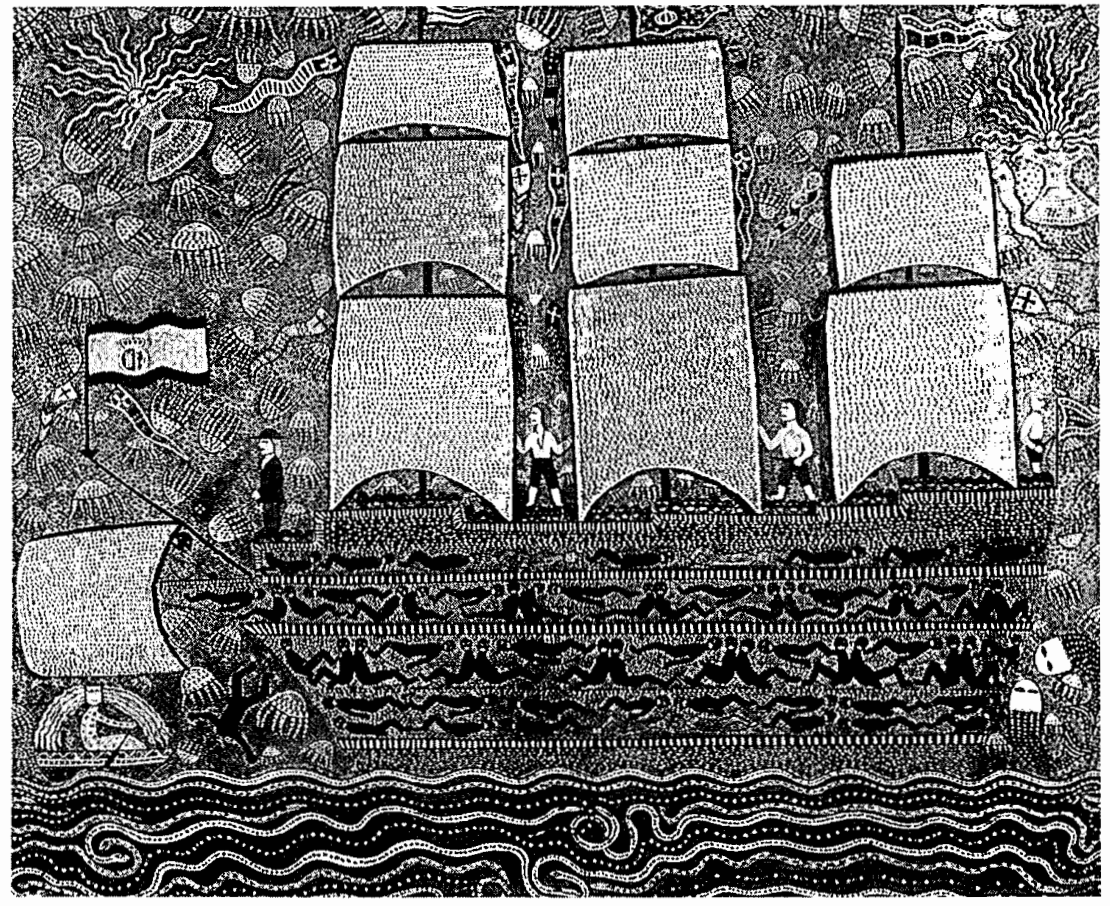

Manuel Mendine, Slave ship, 1976. 
embargo, para los fines de este artículo -que es reflexionar sobre la conformación regional-, los dos aspectos elegidos son suficientes para establecer la complejidad de este horizỏnte económico regional.

\section{CAPITALES E INVERSIONES}

Durante la segunda mitad del siglo XIX tiene lugar el inicio de un reacomodo de capitales, inversiones, apertura de nuevos mercados, rutas mercantiles, etc., que marcó una dinámica diferente a la experimentada hasta esos momentos. Dicha dinámica dio principio al proceso de consolidación de potencias -como Estados Unidos, Alemania e Inglaterra- que impulsaron una política con fuertes atributos de imperialismo y expansionismo. ${ }^{2}$ Para el caso de Estados Unidos, dicho expansionismo fue generado por la amplia difusión de las ideas del Destino Manifiesto y de la Doctrina Monroe. Ambos procesos, de corte intelectual y político, tuvieron una profunda aceptación y difusión en los principales círculos estadunidenses. ${ }^{3}$

En términos generales, a partir de la sexta década de la centuria decimonónica, en América Latina se perfiló una compleja red superpuesta de corrientes de capitales que provenían de varias naciones industrializadas - tanto europeas como de la América del Norte-, las cuales se integraron o pactaron -según fuera necesario-

${ }^{2}$ Rosario Rodríguez ha reflexionado sobre la forma en que se construye este espíritu, ideología, imaginario y política imperialista y expansionista en Estados Unidos. Véase Rodríguez, "Destino", 2000; Rodríguez, "Década", 2000; Rodríguez, Estados, 2001.

$$
{ }^{3} \text { Ibid, pp. } 36 \text { y 76; Muñoz, "1898”, 1998, p. } 34 .
$$

con capitales locales o regionales. ${ }^{4}$ Tal es el caso de la región Golfo-Caribe, en donde convergieron una serie de capitales procedentes de Alemania, Inglaterra, Francia y España, a los cuales -conforme se aproximó el fin del siglo XIX- se les fueron uniendo los de origen estadunidense y canadiense. $^{5}$

Los años de 1880 a 1914 fueron la "Edad de oro" de las inversiones extranjeras en América Latina. En este periodo, tanto el sector público como el privado se vieron beneficiados con importantes flujos de recursos financieros provenientes de las principales potencias europeas y norteamericanas. 6

Los capitales británicos fueron los de mayor antigüedad, y su presencia tuvo un carácter ascendente a lo largo del siglo XIX. Irving Stone sostiene que desde la década de 1820 hasta casi la primera guerra mundial, los británicos tuvieron el primer lugar en inversiones en América Latina; ${ }^{7}$ esta misma idea es compartida por Rory Miller, quien asegura que, al concluir los movimientos de independencia en Latinoamérica, la presencia de las inversiones británicas fue cada vez más evidente. Comerciantes - acompañados de capitales y cargamentos de productos manufacturados, particularmente textiles de algodón- se establecieron a lo largo de las costas tanto del Atlántico como del Pacífico. $^{8}$

Sin embargo, en este lapso compartieron este terreno con otros inversionis-

${ }^{4}$ Marichal, Inversiones, 1995, p. 13.

"Ibid., p. 13; Piqueras, "Capitales", 1998, pp. 163-167.

${ }^{6}$ Marichal, Inversiones, 1995, p. 13.

${ }^{7}$ Stone, Composition, 1987, p. vIl.

${ }^{8}$ Miller, Britain, 1993, p. 2. 
tas de orígenes diferentes. Barbara Stallings demuestra cómo, al finalizar el siglo $\mathrm{XIX}$, si bien Inglaterra era la potencia económica dominante, inversionistas franceses y alemanes comenzaron a exportar grandes sumas de capital hacia el continente americano. Estados Unidos apareció en escena en la segunda mitad de la centuria con inversiones orientadas principalmente a la producción de bienes y servicios que satisficieran las necesidades de su mercado. La misma autora sostiene que en el periodo transcurrido entre 1897 y la primera guerra mundial se dieron los pasos iniciales que prepararon el camino para el surgimiento de Estados Unidos como la principal potencia financiera de América Latina. La banca estadunidense comenzó a desplazar a sus rivales británicos en lo que se refiere a préstamos a los gobiernos y empresas de la región.?

El campo de interés de los inversionistas se dividió por sectores, especializándose en determinadas áreas y regiones. Por ejemplo, los inversionistas británicos se ocuparon principalmente de ferrocarriles, servicios públicos, minas, empresas de tierras, bancos, compañías de seguros y compañías mercantiles. ${ }^{10}$ El grueso de las inversiones se concentró en Argentina, Brasil, México, Chile y Cuba.

Para 1865, del total de inversiones británicas, México albergaba 31.6\%; seguido por Brasil (25.2\%), Colombia (9.1\%) y Venezuela (7.9\%). Conforme se fue aproximando el fin del siglo XIX, la

9 Stallings, Banqueros, 1990, p. 64.

${ }^{10}$ Marichal, Inversiones, 1995 , pp. 15-16. Sobre las inversiones británicas en México o la participación de capitales en algunas obras mexicanas véanse Connolly, Contratista, 1997 y Kuntz, Empresa, 1995. distribución de las inversiones inglesas fue transformándose y diversificándose. En 1875, otros países como Perú y Argentina atrajeron el interés de los inversionistas. Esta tendencia se mantuvo hasta 1913, periodo en el cual Argentina atrajo de manera ascendente a los inversionistas (1885: 18.6\%; 1895: 34.6\%; 1905: $36.8 \%$ y $1913: 41.0$ por ciento). ${ }^{11}$

Los ingleses también invirtieron en préstamos en territorio latinoamericano. En la década de los sesenta, Cuba y México comprendían 39\% del total de los mismos. En este terreno el comportamiento regional fue diferente. Mientras que en México los préstamos siguieron de manera ascendente, en Cuba crecieron sólo hasta que se instauró en la isla el gobierno militar de Estados Unidos, durante el cual los suministros económicos experimentaron una fuerte caída.

En lo que se refiere a las inversiones de origen francés, éstas compitieron con las británicas en varios aspectos, como el tendido de vías férreas y la construcción de obras materiales. También los inversionistas franceses orientaron sus recursos a la banca y establecieron sucursales en países como México, Haití y Bolivia. En Argentina y Brasil los capitales franceses se invirtieron en la compraventa de bonos gubernamentales. ${ }^{12}$

Junto a estos inversionistas estuvieron los de origen alemán, sólo que éstos se dirigieron prioritariamente a la producción y distribución de energía eléctrica y a todo lo que tuviera que ver con tecnología de punta. A decir de Carlos Marichal, en un primer momento los grupos

${ }^{11}$ Stone, Composition, 1987, anexos estadísticos, tabla 41.

${ }^{12}$ Marichal, Inversiones, 1995, p. 16. 
de inversionistas alemanes mostraban interés en el sector financiero otorgando préstamos, principalmente hacia México y Argentina, pero al iniciar la última década del siglo XIX, la dinámica cambió y gran parte de las inversiones se dirigió hacia el sector de la producción y distribución de energía eléctrica, lo cual coincide con el inicio de Alemania como nación industrial exportadora. ${ }^{13}$

En la década de 1880 tiene lugar la aparición de Estados Unidos en el campo de las inversiones de capital en América Latina. Si bien la presencia más fuerte de los estadunidenses comenzó a considerarse realmente importante a partir de los años veinte del siglo $\mathrm{XX}$, lo cierto es que desde cuatro décadas antes, los inversionistas de este país poco a poco habían ido ganando terreno con sus capitales en América Latina.

En un primer momento las operaciones estadunidenses fueron directas, $\mathrm{e}$ inversionistas y exportadores establecidos en el país del norte iniciaron contratos en América Latina. México y el Caribe fueron los primeros campos de acción, más tarde se ampliarían a Centro y Sudamérica. Las áreas de interés fueron las plantaciones de frutas y caña de azúcar, además de la minería y el petróleo. ${ }^{14}$

Es necesario advertir y considerar la situación interna por la que atravesaba Estados Unidos, pues sin duda la guerra de Secesión marcó cambios importantes en el curso de su economía. El expansionismo estadunidense iniciado tiempo atrás, con la guerra sufrió un receso, aunp. 96.

${ }^{13}$ Ibid., p. 17, y Young, "Haciendo", 1995,

${ }^{14}$ Stallings, Banqueros, 1990, p. 64. que una vez concluida ésta, la política expansionista continuó con mayor fuerza.

El triunfo de los estados del Norte sobre los del Sur estableció una dinámica que hizo predominar el interés por el desarrollo de la industria sobre la agricultura. El Norte inauguró campos de inversión hasta esos momentos no explorados o poco explotados, reorientados principalmente al área industrial; este proceso condujo a un control sobre los recursos naturales, la industria y las finanzas desde los grandes centros urbanos como Chicago o Nueva York y a una subordinación del Sur hacia estos centros urbanos. ${ }^{15}$

La situación del Sur después de la guerra fue bastante difícil, pues la agricultura, fuente principal de su desarrollo económico, estaba prácticamente destrozada; granjas abandonadas y campos que antes de la guerra eran tierras prósperas e idóneas para los cultivos sureños, ahora estaban cubiertos de maleza y hierbas; el ganado había sido robado o muerto y las presas destruidas. La industria azucarera de Luisiana estaba devastada y sus tierras abandonadas. ${ }^{16}$ Después de la guerra:

El gran perdedor fue el Sur, que vio destruidas sus líneas férreas, fábricas, grandes extensiones de sus cultivos, edificios y ciudades (Columbia, Richmond, Atlanta). La oligarquía aristocrática, dueña del poder, se vio desmantelada y la región quedó huérfana de jefes políticos durante mucho tiempo. Se les impuso a los sureños el criterio de una mayoría, la demócrata (y dentro de ella la de la minoría radical), que practicó un odio y una intolerancia sectaria. ${ }^{17}$

\footnotetext{
${ }^{15}$ Nevins, Breve, 1994, p. 238.

${ }^{16} \mathrm{Ibid}$., pp. 240-241.

${ }^{17}$ Academia, Atlas, 1988, pp. 731-732.
} 


\section{SECUENCIA}

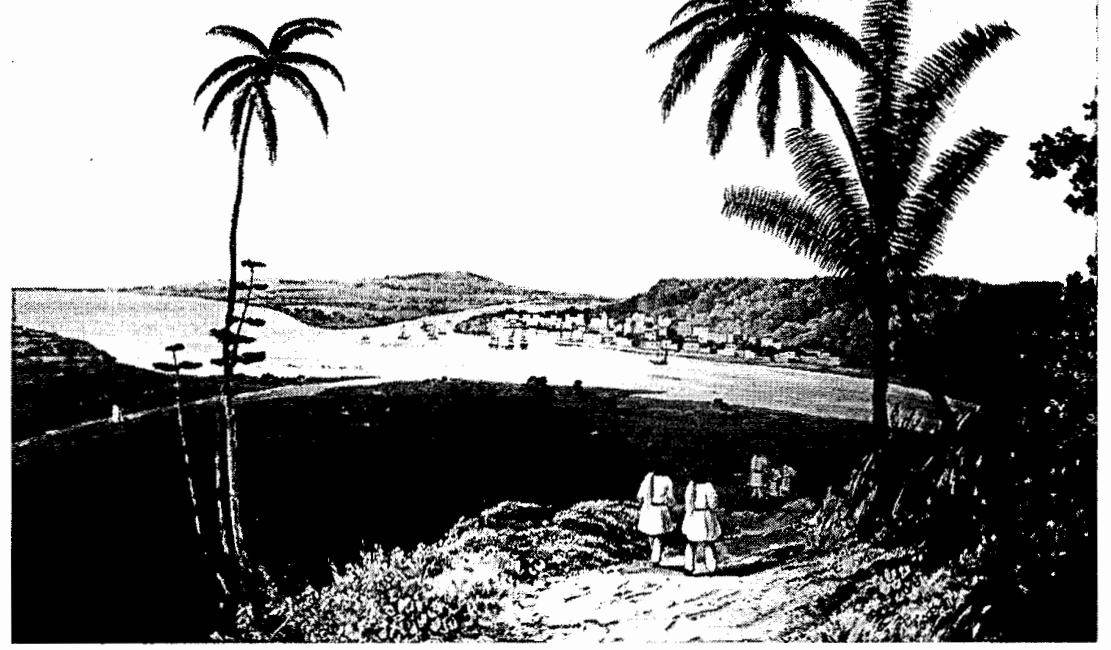

Tampico de Tamaulipas. 
El panorama que prevalecía en la agricultura de Estados Unidos condujo a organizar una política de reconstrucción del Sur. Los ricos industriales, banqueros y comerciantes del Norte vieron en el Sur la posibilidad de invertir capitales que, además de subsanar la situación, se perfilaban como negocios redondos que a corto, mediano y largo plazo redundarían en ganancias significativas. La política de reconstrucción consistió en llevar capitales que activaran la agricultura, pero que también propiciaran el surgimiento de la industria; así, se inauguraron pequeñas fábricas y factorías que en ocasiones tenían que pagar altos intereses a sus prestamistas. En el terreno agrícola, vastas extensiones de tierras fueron sembradas con pinos blancos y amarillos que reactivarían la industria maderera y se fomentó el mejoramiento del cultivo de algodón, que tenía amplia demanda en las industrias textiles. ${ }^{18}$

El Sur se convirtió en plaza de inversión de los grupos económicos del Norte, pero también fue un centro de abastecimiento de materias primas para el desarrollo industrial estadunidense en general. Incluso es posible apuntar que el proceso de inversión de capitales estadunidense inició por su propio territorio, y años más tarde siguió un recorrido -en ocasiones lento- hacia Centro y Sudamérica.

Casi al finalizar el siglo XIX, Estados Unidos se caracterizaba por exportar materias primas e importar bienes manufacturados, pero al avanzar el proceso de industrialización la economía de ese país sufrió algunas transformaciones. De acuerdo con Barbara Stallings, hacia la última década del siglo XIX la mitad de las expor-

${ }^{18}$ Nevins, Breve, 1994, p. 242. taciones estadunidenses eran bienes manufacturados, y la capacidad industrial parecía crecer cada vez más rápido y se alejaba del mercado doméstico. Debido a ello, los empresarios buscaron otros mercados en el extranjero; América Latina ofreció varias ventajas en este campo y resultó más barata por su cercanía geográfica. ${ }^{19}$

Stallings sostiene que la banca estadunidense -aunque de manera paulatinafue ganando terreno, convirtiéndose en un competidor respetable para los inversionistas europeos. En este proceso, el Caribe se constituyó en uno de sus principales campos de acción, donde las relaciones gobierno-banca se conocen como la "diplomacia del dólar". Los estadunidenses demandaron cambios, como la utilización de su moneda para realizar sus transacciones, pues debido a que los capitales con mayor presencia e importancia eran los británicos, las operaciones se realizaban tomando como patrón la libra esterlina.

En la región del Golfo-Caribe el proceso de una multiplicidad de inversiones de capitales resulta bastante nítido. Allí se dio la convergencia de suministros que provenían tanto del viejo continente como del norte de América. Cuba albergaba capitales ingleses y, por supuesto, españoles que tenían su campo en la producción azucarera principalmente. Los inversionistas británicos siguieron la lógica de realizar transacciones de manera directa, tanto con los residentes en la isla como con los que habitaban en la península ibérica.

Aun cuando Cuba continuaba siendo colonia española, los empresarios que invertían en ella fueron ciertamente españoles, pero también ingleses y estaduni-

${ }^{19}$ Stallings, Banqueros, 1990, p. 64. 
denses. Estos últimos reportaron un crecimiento importante y significativo para la economía de la isla. ${ }^{20}$ Las inversiones fueron diversas, y gran parte de ellas se dirigió al sector azucarero, como lo ha demostrado José Piqueras.

El historiador cubano Julio Le Riverend sostenía que durante la segunda mitad del siglo XIX la isla experimentó un proceso de grandes transformaciones, en buena medida influidas por el expansionismo estadunidense, el cual se reflejó en el monto de sus inversiones. Los inversionistas fueron principalmente de los estados norteños de la Unión Americana. Durante la etapa posterior a la guerra de Secesión en Estados Unidos, más allá de la liberación de los esclavos en los estados del Sur, estuvo el deseo de establecer la hegemonía de los estados norteños y dar un impulso mayor al desarrollo industrial y de inversión. ${ }^{21}$ Este proceso condujo a una fase de concentración industrial aparejada al desarrollo de grandes compañías ferroviarias, siderúrgicas y bancos. De forma paralela, se aceleró la demanda de azúcar en varias regiones de Estados Unidos, y Cuba se convirtió en un punto de atracción para los principales surtidores de este producto, que fueron acrecentando su mercado. $^{22}$

Inversionistas de Baltimore, Nueva York y Boston otorgaban créditos para la

${ }^{20}$ Fernández, "Banking", 1987, pp. 7 y ss.; Guerra, Historia, 1952, p. 204; Piqueras, "Capitales", 1998, p. 164.

${ }^{21}$ Le Riverend, Historia, 1972, pp. 187-188.

22 Laura Muñoz ha reflexionado en torno a la forma en que Cuba se convirtió en un punto preponderante dentro de la geopolítica regional. Al respecto véanse sus obras, "Caribe", 1997; "1898", 1998, Geopolítica, 2001. Calavera, "Sistema", 1994, p. 337. producción de azúcar en Cuba. Los capitales fueron destinados principalmente al pago de la mano de obra utilizada en la producción azucarera, la maquinaria para los ingenios y el transporte del mismo. Los empresarios buscaron obtener un producto de calidad y de bajo costo, que lograra satisfacer la alta demanda que éste tenía en gran parte del país.

En la última década del siglo XIX, las inversiones estadunidenses crecieron de manera significativa en relación con las efectuadas hasta ese momento. Para 1895 , el monto de lo invertido en territorio cubano redondeaba los 50000000 de dólares. A pesar de que el principal campo de interés fue la producción de azúcar, junto a ésta la actividad minera también se vio beneficiada con la llegada de dichos capitales. ${ }^{23}$

Más tarde, con compañías como la United Fruit Company, que desde las dos últimas décadas del siglo XIX experimentaron un crecimiento e impulso sorprendentes, se imprimió un ritmo diferente a las relaciones comerciales en la región caribeña. La política económica tenía como característica fundamental el control monopólico del comercio, tal fue el caso de la comercialización de las frutas de origen caribeño y centroamericano.

Con la independencia de Cuba (1898) se aceleró el proceso monopólico en la región. El gobierno militar favoreció a los capitales que provenían de la Unión Americana y prácticamente les concedió el control absoluto del comercio. En la rama

${ }^{23}$ Le Riverend, Historia, 1972, p. 189. Fe Iglesias advierte momentos de crisis financieras importantes para la isla de Cuba en el ocaso colonial debido a la situación de conflicto por la independencia. Iglesias, "Finanzas", 1998, pp. 215-235. 
azucarera esto se hizo más evidente; para 1905 había 25 ingenios propiedad de estadunidenses en territorio cubano, los cuales producían $21 \%$ del total de la zafra. ${ }^{24}$ La segunda mitad del siglo XIX significó para la isla de Cuba un periodo de profundas transformaciones que repercutieron de varias maneras, sin embargo, su sistema económico fue uno de los que más cambios sufrió. Sin duda, la presencia de Estados Unidos, pero sobre todo de los intereses que allí tenían los empresarios e inversionistas del vecino país del norte, abrieron nuevas líneas económicas y beneficiaron la creación de una política de apertura hacia sus inversiones.

Para el caso de la costa del Golfo de México, el proceso de inversión tuvo características singulares, y en Veracruz - principal puerto del país-se realizaban inversiones y movimientos mercantiles con capitales alemanes, ingleses y franceses. Esto tenía un contexto mayor determinado por la política exterior de México. El país requería de inversiones de capital para activar su producción y el sistema económico en general, de allí que la política de comercio exterior buscara una apertura a los inversionistas extranjeros.

$\mathrm{Si}$ bien es cierto que desde inicios del siglo XIX se hallaban capitales extranjeros perfectamente establecidos en las distintas regiones del país, también lo es que necesitaban de nuevos suministros. Los ingresos que México obtenía mediante sus exportaciones se beneficiaban con la llegada de capitales extranjeros. La mayor atracción de estos últimos eran la explotación minera, las comunicaciones, los transportes y la industria eléctrica. ${ }^{25}$

\footnotetext{
${ }^{24}$ Le Riverend, Historia, 1972, p. 207.

${ }^{25}$ Rosenzweig, Historia, 1965 , p. 636,
}

En la segunda mitad del siglo xix el comercio en México tendría una reestructuración fundada en la especialización regional, determinada en buena medida por las exigencias del mercado mundial. El caso de las plantaciones henequeneras en Yucatán es uno de los mejores ejemplos de este proceso, pero también lo es el café veractuzano o las plantaciones de plátano en Tabasco o los cítricos en Nuevo León. ${ }^{26}$

A lo largo del siglo XIX, el comercio en México se vio incrementado con la llegada de capitales provenientes del exterior. A decir de Inés Herrera Canales, las relaciones comerciales de México con el exterior se realizaban fundamentalmente con Europa y América del Norte, y en forma secundaria con el Caribe, Centroamérica, Sudamérica y Asia. ${ }^{27}$

En términos generales la inversión extranjera fue en constante aumento, y conforme transcurrió el siglo XIX llegaron al territorio mexicano capitales provenientes de Europa (franceses, ingleses, alemanes y españoles). El porfiriato significó un auge para las inversiones extranjeras que crecieron a lo largo de este periodo. De acuerdo con Fernando Rosenzweig, para 1911. la inversión extranjera sobrepasaba los 3400 millones de pesos, de los cuales sólo 110000000 se invirtieron antes de 1884. Los montos de estos capitales se dividieron de la siguiente manera: $62 \%$ venían de países europeos y $38 \%$ de Estados Unidos. Sin embargo, es necesario advertir que México representó una zona secundaria para la inversión europea, pues del monto total de inversión, sólo $5.5 \%$, se destinaba a México, mientras que el resto de Latinoamérica absorbía $29 \%$. No

\footnotetext{
${ }^{26}$ Cerutti, "Contribuciones", 1990, pp. 31-36.

${ }^{27}$ Herrera, Comercio, 1977, p. 89.
} 


\section{SECUENCIA}

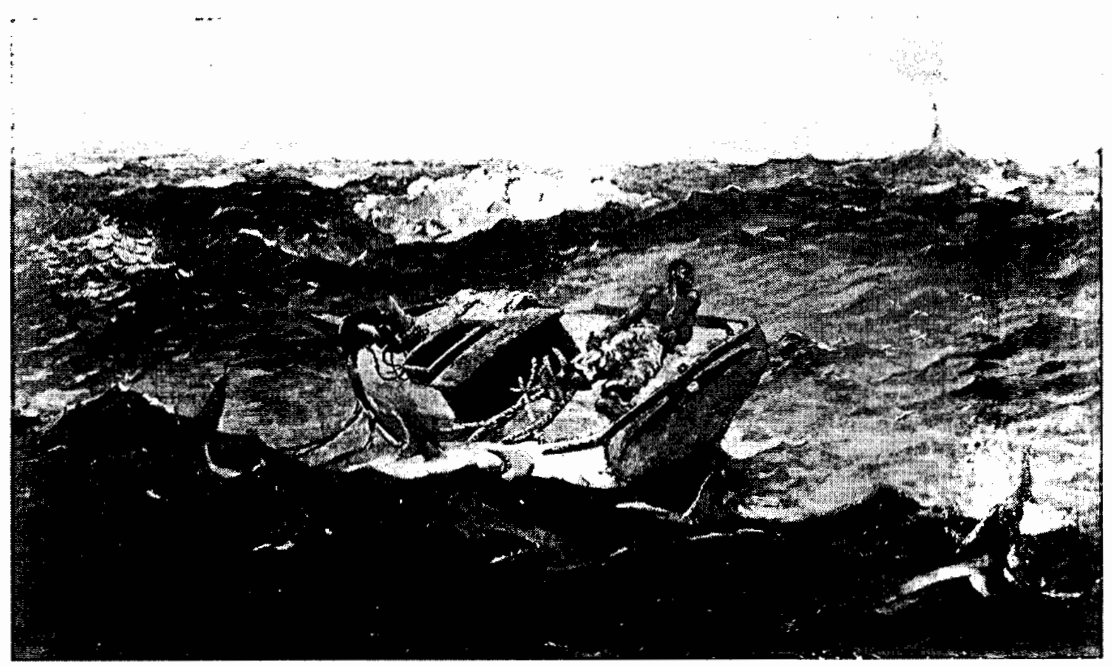

Winslow Hamer, The Gulf Stream, 1899. 
así para los capitales de Estados Unidos, para los cuales México resultaba uno de sus principales campos de interés, pues los empresarios estadunidenses destinaban $45.5 \%$ de sus inversiones al territorio mexicano. 28

Estos capitales se sumaron al ya existente y en algunos casos operaron de manera paralela o conjunta. En las costas del Golfo de México, este proceso condujo a una consolidación de capitales regionales. En el caso de Veracruz, esto se tradujo en un fortalecimiento de las actividades mercantiles; el puerto veracruzano, que tradicionalmente era un sitio importante para esta actividad, con este proceso se benefició aún más.

Por lo que toca a la península de Yucatán, en ésta también se observó la llegada de capitales extranjeros en forma de préstamos de los bancos estadunidenses, con lo cual se inició el despegue de la producción henequenera en gran escala. ${ }^{29}$ Los inversionistas estadunidenses vieron con buenos ojos el cambio de cultivos y la importancia que el henequén adquirió en las haciendas yucatecas, pues durante la primera mitad del siglo XIX había constituido un cultivo secundario, pero al mediar el siglo registró gran demanda, tanto en Estados Unidos como en Inglaterra y Francia. Los inversionistas estadunidenses dirigieron capitales a los propietarios de las haciendas henequeneras de la península. A decir de Villanueva Mukul,

Como consecuencia de la expansión de la economía norteamericana y de sus necesidades, llegaron a Yucatán las primeras inyecciones de capital para la actividad heneque-

${ }^{28}$ Rosenzweig, Historia, 1965, p. 637.

29 Villanueva, Tomamos, 1984, p. 108. nera. Los préstamos otorgados por los bancos norteamericanos fueron en realidad el origen de la producción henequenera a gran escala. ${ }^{30}$

Estas inversiones coincidieron con una demanda de las mismas para las haciendas de la región, las cuales, debido a los conflictos que tuvieron lugar durante el siglo $\mathrm{XIX}$, habían quedado escasas de circulante. El cultivo del henequén representaba un problema debido a que, para alcanzar su producción, se requerían de seis a siete años de maduración.

Por lo que respecta a las costas del sureste de Estados Unidos, y concretamente a Nueva Orleans, en este lugar se establecieron comerciantes de origen francés e inglés que ocuparon el sitio como su principal centro de operaciones. El fenómeno en ese puerto fue similar al de las costas del Golfo de México; capitales que en su momento fueron importados pero que, al paso del tiempo, se convirtieron en locales, contaban con un asentamiento importante y habían generado una dinámica propia. Sin embargo, requerían del suministro de nuevos recursos que les permitieran crecer y satisfacer las demandas de un mercado interior. La producción de arroz y trigo, así como el comercio que en este puerto se desarrollaba requerían ser modernizados.

La costa sureste de Estados Unidos no era una zona de alto desarrollo de capitales

${ }^{30} \mathrm{lbid}$, p. 108. El auge henequenero en Yucatín favoreció la consolidación de fuertes grupos económicos en la región que basaron su riqueza, en buena media, en la gran demanda de estos productos. Véase el libro de Wells y Joseph, Summer, 1996, en el que se analiza la conformación de estos grupos y su lucha por el poder. 
locales como la del noreste. Aun cuando los capitales que allí se encontraban establecidos eran capaces de mantener un movimiento mercantil local, requerían de un impulso para insertarse en una dinámica mayor. El puerto de Nueva Orleans era un acceso importante para desarrollar las actividades comerciales en la Unión Americana; varios comerciantes del interior, así como los locales, encontraban en este puerto su principal plaza de acción. Esto despertaba en los inversionistas europeos el interés por realizar transacciones mercantiles y de inversión en este sitio.

Las inversiones en Nueva Orleans y sus alrededores fueron destinadas a las vías de comunicación. El río Mississippi -canal de comunicación por excelencia del centro-sur de Estados Unidos- se vio favorecido por esta política, y se buscó mejorar las condiciones de navegación mediante la construcción de modernas embarcaciones o labores de drenado en sus cauces.

Entre la política de inversión en las tierras del Sur de Estados Unidos, tanto de los inversionistas norteños como de los extranjeros, estuvo la compra de granjas y plantaciones, con lo cual se buscaba reanimar la producción agrícola. También algunos empresarios norteños invirtieron grandes sumas en ferrocarriles, bosques, carbón y acero. Todo esto provocó que los estados del Sur poco a poco volvieran al mercado mundial con la exportación de sus productos. ${ }^{31}$

En resumen, durante la segunda mitad del siglo XIX, tuvo lugar en la región del Golfo-Caribe una serie de flujos de capitales que buscaron inyectar recursos a

${ }^{31}$ Morrison, Breve, 1980, p. 450. las actividades económicas, ya fuera en la inversión directa en áreas productivas o en acciones mercantiles, toda vez que fueron conformando una región económica en donde la expansión estadunidense fue evidente.

\section{LA COMPOSICIÓN DE LA PRODUCCIÓN REGIONAL}

El expansionismo del capitalismo mundial condujo a cambios y modificaciones en los sistemas productivos, de mercado y de consumo, pues los tres adquirieron un nuevo dinamismo en busca de mejorar y aumentar la producción, el mercado y los consumidores; esto tanto en la actividad industrial como en la agropecuaria. La región del Golfo-Caribe no escapó a este proceso, y su desarrollo respondió a las condiciones propias de la región y los productos originarios de la misma.

Los capitales y las inversiones recibidas se suministraron en sectores de acuerdo con los requerimientos del mercado mundial y en las áreas productivas propias de la región. En Cuba, por ejemplo, ante la fuerte demanda de su producto básico, el azúcar, los inversionistas se dirigían a inyectar recursos a los campos e ingenios destinados a la actividad azucarera. En la isla, la guerra de los Diez Años marcó de manera significativa sus actividades comerciales; con el conflicto armado la economía cubana experimentó una reestructuración marcada por una alta concentración industrial, principalmente en los ingenios, los cuales fueron poco a poco incorporando innovaciones tecnológicas propias de la revolución industrial. ${ }^{32}$

\footnotetext{
${ }^{32}$ Guerra, Historia, 1952, t. VII, pp. 151-152.
} 
La concentración de la industria azucarera en Cuba se inició con la liquidación progresiva de la esclavitud y la amplia demanda del producto en las refinerías estadunidenses. La producción azucarera en la isla mantuvo cierta estabilidad entre los años de 1860 y 1890 , pero entre 1896 y 1902 experimentó una caída -motivada principalmente por la situación bélica de la isla-, aunque se recuperó a partir de 1903, cuando la producción ascendió, tal como lo muestra la gráfica $1 .^{33}$

Al finalizar el siglo XIX, Cuba contaba con 173 ingenios distribuidos de la siguiente manera: 66 en la provincia de Santa Clara, 41 en la de Matanzas, 32 en Oriente, 18 en La Habana, nueve en Camagüey y siete en Pinar del Río, ${ }^{34}$ siendo la región central de la isla la de mayor producción.

Por lo que hace a la producción de tabaco, éste siguió un camino diferente, pues su dinámica estuvo marcada y determinada principalmente por la demanda externa. Guerra sostiene que en "la industria cubana del tabaco [...] a medida que aparecieron las grandes fábricas, sus necesidades de aprovisionamiento de materia prima las incitó a controlar las plantaciones, mediante compra o fomento directo". ${ }^{35} \mathrm{Al}$ mediar la centuria decimonónica, el mercado interno de la isla se componía de 1217 tabaquerías, de las cuales 516 estaban ubicadas en $\mathrm{La} \mathrm{Ha-}$ bana y sus barrios. ${ }^{36}$

${ }^{33}$ Es necesario explicar la caída de la producción entre los años de 1894-1900, debido a la situación de inestabilidad interna de la isla.

${ }^{34}$ Le Roy, Anuario, 1914, pp. 99-105.

${ }^{35}$ Guerra, Historia, 1952, t. vil, p. 198.

${ }^{36}$ Le Roy, Anuario, 1914, p. 108.
Además del azúcar y el tabaco, la isla era productora de ganado, y junto con la actividad minera ocuparon un lugar destacado dentro de su economía, sobre todo en la primera mitad del siglo XIX. Sin embargo, la minería fue afectada de manera considerable por la guerra de los Diez Años, y sus labores fueron suspendidas. Empero, el proceso de industrialización por el que atravesaba Estados Unidos condujo a los industriales y empresarios estadunidenses a ver en la isla la posibilidad de surtirse de metales como el cobre.

Por lo que hace a la ganadería, entre 1878 y 1902 se encontraba en una situación difícil, producto de una mala organización y planeación. Ramiro Guerra advierte que el estado de la ganadería antes de 1868 era precario, y con los conflictos armados la situación empeoró, reduciendo cada vez más su importancia como generadora de recursos dentro de la economía cubana. ${ }^{37}$

En el caso de Estados Unidos, el panorama de su producción era bastante desolado, debido fundamentalmente a la guerra de Secesión. Cabría recordar que los estados del Sur-que fueron predominantemente puntales de la agricultura estadunidense- habían quedado devastados como consecuencia de la guerra, y su recuperación requirió de dos cosas: por un lado, capitales e inversionistas y, por el otro, tiempo para sobreponerse y recuperar sus niveles de producción. Por ejemplo, el caso de la caña de azúcar en Luisiana resulta muy ilustrativo para analizar la inestabilidad de su producción, pues aun en sus mejores épocas productivas no

${ }^{37}$ Guerra, Historia, 1952, t. viI, pp. 201-202. 


\section{SECUENCIA}

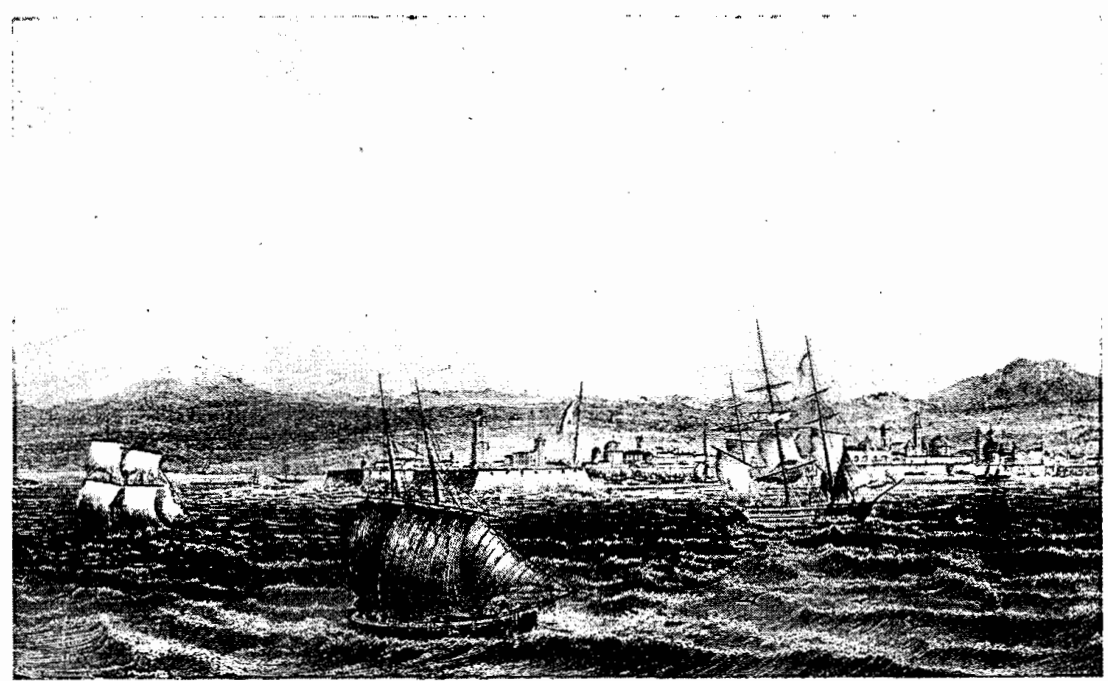

Juan Mauricio Rugendas, The port of Veracruz with the Castle of San Juan de Ulua. 
alcanzaba los niveles de la isla de Cuba. El estado sureño era el principal abastecedor de la demanda estadunidense y a lo largo de la segunda mitad del siglo XIX, sus niveles productivos registraron altibajos constantes (véase gráfica 2).

Ello hacía contrastar notablemente el consumo y la demanda interna de este producto. El cuadro 1 pone de manifiesto la diferencia entre el consumo de azúcar y la producción interna. De él se desprende que Estados Unidos no contaba con un sistema productivo capaz de satisfacer su demanda interna, por lo que tenía que recurrir a la importación de productos como los de Cuba o México.

En lo referente a las costas mexicanas del Golfo de México, en ellas se desarrollaba una actividad comercial amplia, creciente y variada en productos que eran comercializados en sus puertos, algunos de ellos originarios de las regiones costeras o próximas a ellas, como fue el caso del henequén, y otros traídos de la región central.

Desde 1877, el henequén constituía el principal producto de exportación de México, después de los metales preciosos. Este producto había adquirido gran importancia al concluir la guerra de Castas, la cual no solamente había significado una derrota militar para los hacendados de la península de Yucatán, que eran importantes productores de azúcar, tabaco y algodón, sino que, al poco tiempo de concluida la guerra, estos campos habían quedado prácticamente arrasados. Los hacendados yucatecos comenzaron a recibir financiamiento para rehabilitar sus haciendas y sembrar henequén; estos financiamientos provenían principalmente de Estados Unidos y, a decir de Eric Villanueva:
La producción del henequén nacía con el "pecado original" de estar ligada al mercado internacional y ser promovida desde el exterior para cubrir las necesidades de la economía internacional, particularmente la de Estados Unidos. ${ }^{38}$

En la segunda mitad del siglo XIX, la producción del henequén fue en ascenso, y para 1860 se registraban 2600 hectáreas que, nueve años más tarde, aumentaron a 16000 -con una producción de 13800 toneladas. El crecimiento de la industria henequenera fue tan vertiginoso que demandaba mejores técnicas en su cultivo, y la utilización de tecnología avanzada para su cosecha, como el uso del vapor para la raspa del producto. ${ }^{39}$

El café también fue otro producto que circulaba libremente por la región, y el cosechado en México tenía un amplio mercado. Lo mismo sucedía con las maderas tintóreas, como el palo de tinte y el palo de Campeche, que mantenían un lugar destacado dentro de las exportaciones mexicanas; el ixtle tuvo también amplia demanda, tanto en Estados Unidos como en Alemania, Gran Bretaña, Francia, Bélgica y Holanda; las pieles eran mercancías mexicanas de gran producción, ya fueran de animales domésticos o de cacería; el ganado vacuno se criaba en vastas zonas del país y se exportaba hacia Estados Unidos. ${ }^{40}$ Junto con estos productos estaban el azúcar y el tabaco que se producían en amplias extensiones de tierra.

También la región norte era productora de diversos artículos que encontraban

\footnotetext{
${ }^{38}$ Villanueva, Tomamos, 1984, p. 71.

${ }^{39}$ lbid., pp. 72-73.

${ }^{40}$ Rosenzweig, Historia, 1965, pp. 666-687.
} 


\section{SECUENCIA}
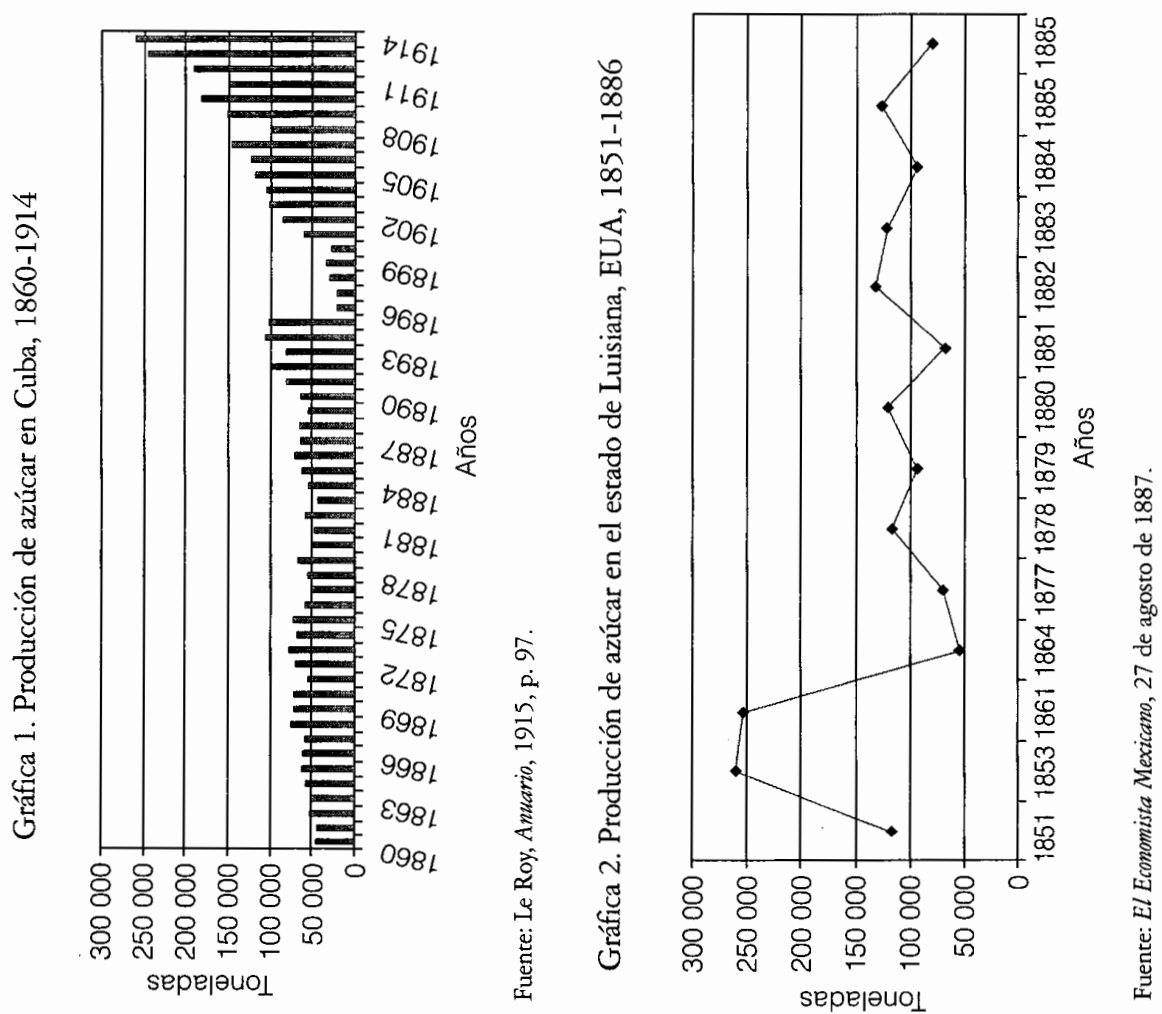
Cuadro 1. Comparación entre el consumo y la producción de azúcar en Estados Unidos, 1877-1886

$\begin{array}{llrc}\text { Año } & \text { Consumo } & \text { Producción } & \begin{array}{c}\text { Porcentaje de producción } \\ \text { en relación con el consumo }\end{array} \\ 1877 & 745000 & 70700 & 9.49 \\ 1878 & 773000 & 118000 & 15.2 \\ 1879 & 832000 & 94000 & 11.29 \\ 1880 & 922000 & 120800 & 13.10 \\ 1881 & 1009000 & 68000 & 6.73 \\ 1882 & 1078000 & 133400 & 12.37 \\ 1883 & 1 & 122400 & 10.51 \\ 1884 & 1264000 & 94300 & 7.45 \\ 1885 & 1245000 & 128000 & 10.28 \\ 1886 & 1388000 & 80000 & 5.76\end{array}$

Fuente: El Economista Mexicano, 27 de agosto de 1887.

demanda y mercado en la región GolfoCaribe. El puerto de Tampico funcionó como centro comercial y de operaciones mercantiles que se abastecía con artículos y efectos procedentes de San Luis Potosí, Zacatecas, Aguascalientes, Durango y Guanajuato, incluso Coahuila y Nuevo León, además de algunos otros de regiones montañosas como las Huastecas. ${ }^{41}$

La plata constituía un producto de exportación importante que salía por los puertos de Veracruz y Tampico. De este último se embarcaba en vapores ingleses y de bandera estadunidense con dirección al viejo continente o a Estados Unidos; Nueva Orleans fue la entrada principal de plata en la Unión Americana.

En el puerto de Tampico la actividad comercial eventualmente compitió en importancia con la de Veracruz. En esta pla- za se establecieron comerciantes que tomaron como su centro de acción a la propia plaza porteña, lo cual la colocaba como centro comercial de gran importancia regional. El comercio estuvo conformado por comerciantes locales, pero también por extranjeros, principalmente españoles, franceses, ingleses y estadunidenses. Los giros comerciales fueron variados y estuvieron compuestos por productos locales y extranjeros; de Estados Unidos llegaban telas de algodón o mantas, de Francia vinos y sederías, de Alemania la ferretería y de Inglaterra fierros y tejidos. ${ }^{42}$

En conclusión, es posible señalar que en el Golfo-Caribe, durante la segunda mitad del siglo XIX, tuvo lugar un proceso económico que determinó en la región

${ }^{42}$ Ibid., p. 105. 


\section{SECUENCIA}

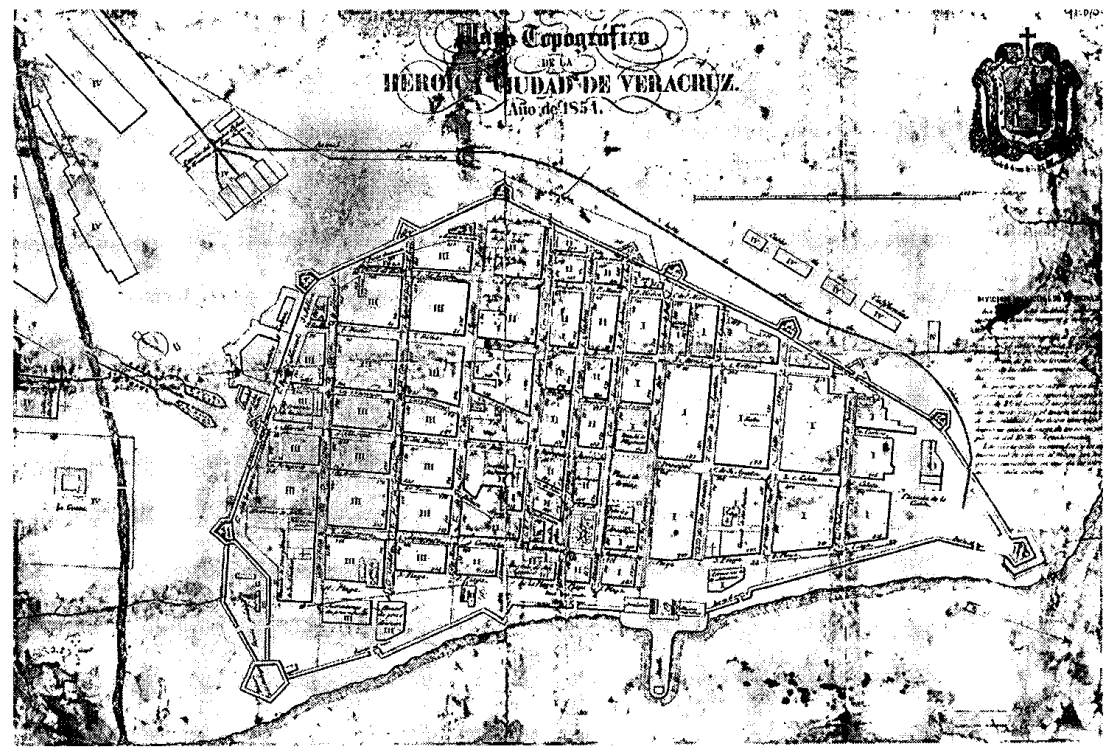

Plano topográfico de la heroica ciudad de Veracruz, 1854. 
una dinámica propia caracterizada por movimientos de capitales, mercados, flujos y abastecimiento de productos. Dicho proceso derivó en la conformación de un espacio económico que experimentaba profundas transformaciones, las cuales se reflejaban en cambios estructurales y coyunturales y planteaban la necesidad, ciertamente, de consolidar mercados, pero también, la posibilidad de extenderlos hacia otros espacios. Si bien el mercado europeo permaneció como un punto de destino importante para el comercio caribeño, Estados Unidos comenzó a ganar terreno en este sentido y poco a poco fue adquiriendo un nivel de supremacía comercial en la región. Lo anterior generó un proceso de expansionismo económico alimentado en buena medida por el ambiente ideológico y político que crearon, por un lado, el Destino Manifiesto y, por el otro, la Doctrina Monroe.

Los productos, efectos y mercancías que circularon por las aguas del Golfo de México y del Caribe conformaron un comercio regional amplio y diverso, integrado por productos regionales y extranjeros. El comercio adquirió un ritmo intenso que requirió de la definición de rutas mercantiles nuevas que se unieron a las existentes, trazando una comunicación marítima importante en la región.

Este proceso económico y comercial desembocó en la creación de una visión expansionista conformada por estrategias de control y dominio, pues a partir del mismo se suscitó un mayor interés por ir incorporando a esta dinámica otras regiones, como el gran Caribe, Centro y Sudamérica. De esta forma, los primeras lustros del siglo XX serían testigos de cómo esta visión expansionista sería encabezada por Estados Unidos, que asumiría el control del comercio regional y, por lo tanto, el del espacio marítimo. Si bien continuaría compartiendo el área con otras potencias, su liderazgo y dominio poco a poco fueron definitivos.

\section{HeMerografía}

El Economista Mexicano, México, D. F.

\section{BiBLIOGRAFÍA}

-Academia de Ciencias de Cuba y Academia de Ciencias de la URSS, Atlas nacional de Cuba en el décimo aniversario de la vevolución, ACC/AC-URSS, La Habana, 1979.

-Calavera Vayá, Anamaría, "El sistema crediticio español del siglo XIX y su reflejo en Cuba: los comerciantes banqueros" en Cuba, la perla de las Antillas. Actas de las I Jornadas sobre Cuba y su bistoria, Ediciones Doce Calles, Madrid, 1994.

-Cerutti, Mario, "Contribuciones recientes y relevancia de la investigación regional sobre la segunda parte del siglo XIX" en Carlos Martínez Assad (coord.) Balance y perspectivas de los estudios regionales en México, Centro de Investigaciones Interdisciplinarias de Humanidades-Universidad Nacional Autónoma de México/Porrúa, México, 1990, pp. 26-60.

-Connolly, Pricilla, El contratista de don Porfirio: obras prublicas y modernización desigual, Fondo de Cultura Económica/El Colegio de Michoacán/Universidad Autónoma Metropolitana, México, 1997.

-Contreras, Julio, "Los comerciantes del porfiriato en el puerto de Veracruz, 1880-1890", tesis de licenciatura, Facultad de Historia-Universidad Veracruzana, Xalapa, 1992.

-Fernández, Susan Jane, "Banking, credit, and colonial finance in Cuba, 1878-1895", tesis doctoral, University of Florida, EUA, 1987. 
-González Salas, Carlos, Tampico es lo azul: Crónicas de Tampico, Ciudad Madero y Ciudad Altamira, M. A. Porrúa, México, 1990.

-Guerra, Ramiro et al., Historia de la nación cubana, Editorial de la Nación Cubana, La Habana, 1952.

-Herrera Canales, Inés, El comercio exterior de México, 1821-1875, El Colegio de México, México, 1977.

—_ "La circulación (comercio y transporte en México entre los años de 1880 y 1910)" en Ciro Cardoso (coord.), México en el siglo XIX (1821-1910). Historia económica y de la estructura social, Editorial Nueva Imagen, México, 1983, pp. 193-225.

-Iglesias García, Fe, "Las finanzas de Cuba en el ocaso colonial", Revista de Indias, vol. IVIII, núm. 212, 1998, España, pp. 215-235.

-Kuntz Ficker, Sandra, Empresa extranjera y mercado interno. El Ferrocarril Central Mexicano, 1880-1907, El Colegio de México, México, 1995.

-Le Riverend, Julio, Historia económica de Cuba, Ariel, España, 1972.

-Le Roy y Cassá, Jorge, et al., Anuario estadístico de la república de Cuba, Imprenta Siglo XX, La Habana, 1914.

-Marichal Salinas, Carlos, Las inversiones extranjeras en América Latina, 1850-1930. Nuevos debates y problemas en bistoria económica comparada, Fideicomiso Historia de las Américas/El Colegio de México/Fondo de Cultura Económica, México, 1995.

-Miller, Rory, Britain and Latin America in the Nineteenth and Twentieth Centuries, Longman Publishing, Nueva York, 1993.

-Miño Grijalva, Manuel, "Tendencias generales de la relaciones económicas entre México y España" en Clara E. Lida (coord.), Tres aspectos de la presencia española en México durante el porfiriato, El Colegio de México, México, 1981.

-Morrison, Samuel Eliot et al. Breve bistoria de los Estados Unidos, Fondo de Cultura Económica, México, 1980.
-Muñoz Mata, Laura, "El Caribe y México a finales del siglo XIX, 1890-1898", Revista Mexicana del Caribe, núm. 3, año II, 1997, México, pp. 75-111.

-, "1898, el fin de un ciclo de política mexicana en el Caribe", Secuencia, núm. 42, septiembre-diciembre, 1998, México, pp. 29-47.

- Geopolítica, seguridad nacional y política exterior. México y El Caribe en el siglo XIX, Instituto de Investigaciones Dr. José María Luis Mora/Instituto de Investigaciones HistóricasUniversidad Michoacana de San Nicolás de Hidalgo, México, 2001.

-Nevins, Allan y Henry Steell Commager, Breve bistoria de los Estados Unidos, Fondo de Cultura Económica, México, 1994.

-Piqueras Arenas, José A., "Capitales en el azúcar. Los hacendados cubanos ante la rentabilidad económica y la oportunidad de inversión (1878-1895)", Revista de Indias, vol. IVIII, núm. 212, 1998, España, pp. 163-193.

-Rodríguez Díaz, Rosario, "El Destino Manifiesto y el pensamiento expansionista de $\mathrm{Al}$ fred Thayer Mahan", tesis de doctorado, Facultad de Filosofía y Letras-UNAM, México, 2000.

___ "Una década de la Doctrina Monroe en el Caribe. La perspectiva de Alfred Thayer Mahhan. 1895-1905” en María del Rosario Rodríguez Díaz (coord.), El Caribe. Intereses geopolíticos y dominación colonial, Instituto de Investigaciones Históricas-Universidad Michoacana de San Nicolás de Hidalgo, México, 2000, pp. 133-156. la visión de Andrew Carnegie, 1889-1901, Instituto de Investigaciones Históricas-Universidad Michoacana de San Nicolás de Hidalgo, México, 2001.

-Rosenzweig, Fernando et al., Historia moderna de México. El porfiriato vida económica, Editorial Hermes, México, 1965.

-Stallings, Barbara, Banqueros para el tercer 


\section{SECUENCIA}

mundo. Inversiones de cartera de Estados Unidos a América Latina, 1890-1986, Consejo Nacional Para la Cultura y las Artes/Alianza Editorial Mexicana, México, 1990.

-Stone, Irving, The Composition and distribution of British investment in Latin American, 1865 to 1913, Garland Publishing Inc., Nueva York y Londres, 1987.

- Villanueva Mukul, Eric, Así tomamos las tierras. Henequén y haciendas en Yucatán durante el porfiriato, Yucatán, México, 1984 (Colección Raíces).
-Young, Eric van, "Haciendo historia regional: consideraciones metodológicas y teóricas" en Pedro Pérez Herrero (comp.), Región e bistoria en México (1700-1850), Instituto Mora, México, 1991, pp. 99-122.

-Wells, Allen y Gilberte M. Joseph, Summer of Discontent, Seasons of Upheaval. Elite Politics and Rural Insurgency in Yucatan, 1876-1925, Universidad de Stanford, California, 1996. 